INT. J. REMOTE SENSING, 2002, VOL. 23, NO. 18, 3579-3594

\title{
Landscape-scale characterization of cropland in China using Vegetation and Landsat TM images
}

\author{
X. XIAO ${ }^{1,2, *}$, S. BOLES ${ }^{1}$, S. FROLKING ${ }^{1}$, W. SALAS ${ }^{1}$, \\ B. MOORE III ${ }^{1}$, C. LI ${ }^{1}$, L. HE ${ }^{3}$ and R. ZHAO ${ }^{3}$ \\ ${ }^{1}$ Complex Systems Research Center, Institute for the Study of Earth, Oceans \\ and Space, University of New Hampshire, Durham, NH 03824, USA \\ ${ }^{2}$ Institute of Geographical Science and Natural Resources, Chinese Academy of \\ Sciences, Beijing, China. \\ ${ }^{3}$ Nanjing Institute of Geography and Limnology, Chinese Academy of \\ Sciences, Nanjing China.
}

(Received 14 August 2000; in final form 18 June 2001)

\begin{abstract}
In this landscape-scale study we explored the potential for multitemporal 10-day composite data from the Vegetation sensor to characterize land cover types, in combination with Landsat TM image and agricultural census data. The study area $(175 \mathrm{~km}$ by $165 \mathrm{~km})$ is located in eastern Jiangsu Province, China. The Normalized Difference Vegetation Index (NDVI) and the Normalized Difference Water Index (NDWI) were calculated for seven 10-day composite (VGT-S10) data from 11 March to 20 May 1999. Multi-temporal NDVI and NDWI were visually examined and used for unsupervised classification. The resultant VGT classification map at $1 \mathrm{~km}$ resolution was compared to the TM classification map derived from unsupervised classification of a Landsat 5 TM image acquired on 26 April 1996 at $30 \mathrm{~m}$ resolution to quantify percent fraction of cropland within a $1 \mathrm{~km}$ VGT pixel; resulting in a mean of $60 \%$ for pixels classified as cropland, and $47 \%$ for pixels classified as cropland/natural vegetation mosaic. The estimates of cropland area from VGT data and TM image were also aggregated to county-level, using an administrative county map, and then compared to the 1995 county-level agricultural census data. This landscape-scale analysis incorporated image classification (e.g. coarse-resolution VGT data, fineresolution TM data), statistical census data (e.g. county-level agricultural census data) and a geographical information system (e.g. an administrative county map), and demonstrated the potential of multi-temporal VGT data for mapping of croplands across various spatial scales from landscape to region. This analysis also illustrated some of the limitations of per-pixel classification at the $1 \mathrm{~km}$ resolution for a heterogeneous landscape.
\end{abstract}

\section{Introduction}

Remote sensing technology has been widely used in agriculture for estimating cropland areas and crop production. Over the last few decades, regional to global

* Present address: Complex Systems Research Center, Institute for the Study of Earth, Oceans and Space, University of New Hampshire, Durham, NH 03824, USA; e-mail: xiangming.xiao@unh.edu 
scale mapping and monitoring of croplands have been largely dependent upon the National Oceanic and Atmospheric Administration (NOAA) Advanced Very High Resolution Radiometer (AVHRR) data (Quarmby et al. 1992, Bachelet 1995, Zhao et al. 1996, Wang and Xia 1996, Fang 1998, Loveland et al. 2000). The AVHRR sensor was originally designed for meteorological observation and has only two spectral bands that are useful for vegetation observations (red and near infrared bands, see table 1). Applications of AVHRR data to characterize cropland and other land cover types have been constrained by its limited number of spectral bands for vegetation observations. In an earlier study that compared AVHRR-derived cropland estimates with the agricultural census of cropland in China (Frolking et al. 1999), large discrepancies (in the range of $50 \%$ to $100 \%$ ) between remote sensing estimates and agricultural census data were observed across the scales of county, province and region. These were attributed to inaccuracies in both remote sensing and census data.

In comparison with the NOAA AVHRR sensors, the Vegetation (VGT) sensor (aboard the SPOT-4 satellite) was designed with a number of improvements for studying the vegetation and land surface. For instance, the VGT instrument has four spectral bands that are equivalent to the spectral bands of Landsat TM (table 1). The blue band is primarily used for atmospheric correction. The mid-infrared band is highly sensitive to soil moisture content, vegetation cover and leaf moisture content. The VGT instrument provides daily images of the global land surface at $1 \mathrm{~km}$ spatial resolution. Therefore, VGT data may have the potential for improved characterization of land cover types across large spatial scales (landscape, regional, continental, global).

In this study we used multi-temporal VGT data to conduct a landscape-scale land cover classification for a study area $(175 \mathrm{~km}$ by $165 \mathrm{~km})$ in eastern Jiangsu Province, China (figure 1), where agricultural land cover (a winter wheat and paddy rice double cropping system) dominates. The VGT-derived classification results were compared to Landsat TM-derived classification results, and to agricultural census data. The objective of this landscape-scale study was twofold: (1) to develop a better understanding of the characteristics of multi-temporal VGT data in relation to various land cover types; and (2) to assess the potential of VGT data for cropland characterization at large spatial scales.

\section{Vegetation sensor data and image classification}

SPOT Image Inc. provides three standard VGT products to users: VGT-P (Physical product), VGT-S1 (daily synthesis product) and VGT-S10 (10-day synthesis product). For each month there are three 10-day composites: days 1-10, days 11-20, and day 21 to the last day of the month. VGT-S10 data are generated using the

Table 1. A comparison of Vegetation (VGT) in SPOT 4, Landsat TM and AVHRR sensors.

\begin{tabular}{lccc}
\hline & VGT $(\mathrm{nm})$ & TM $(\mathrm{nm})$ & AVHRR $-11(\mathrm{~nm})$ \\
\hline Blue band & B0 $(430-470)$ & TM1 $(450-520)$ & - \\
Red band & B2 $(610-680)$ & TM3 $(630-690)$ & CH1 $(580-680)$ \\
Near-infrared band & B3 $(780-890)$ & TM4 $(760-900)$ & CH2 $(725-1100)$ \\
Mid-infrared band & MIR $(1580-1750)$ & TM5 $(1550-1750)$ & - \\
Spatial resolution & $1 \mathrm{~km}$ & $30 \mathrm{~m}$ & $1 \mathrm{~km}$ \\
Revisit time & daily & 16 days & daily \\
\hline
\end{tabular}




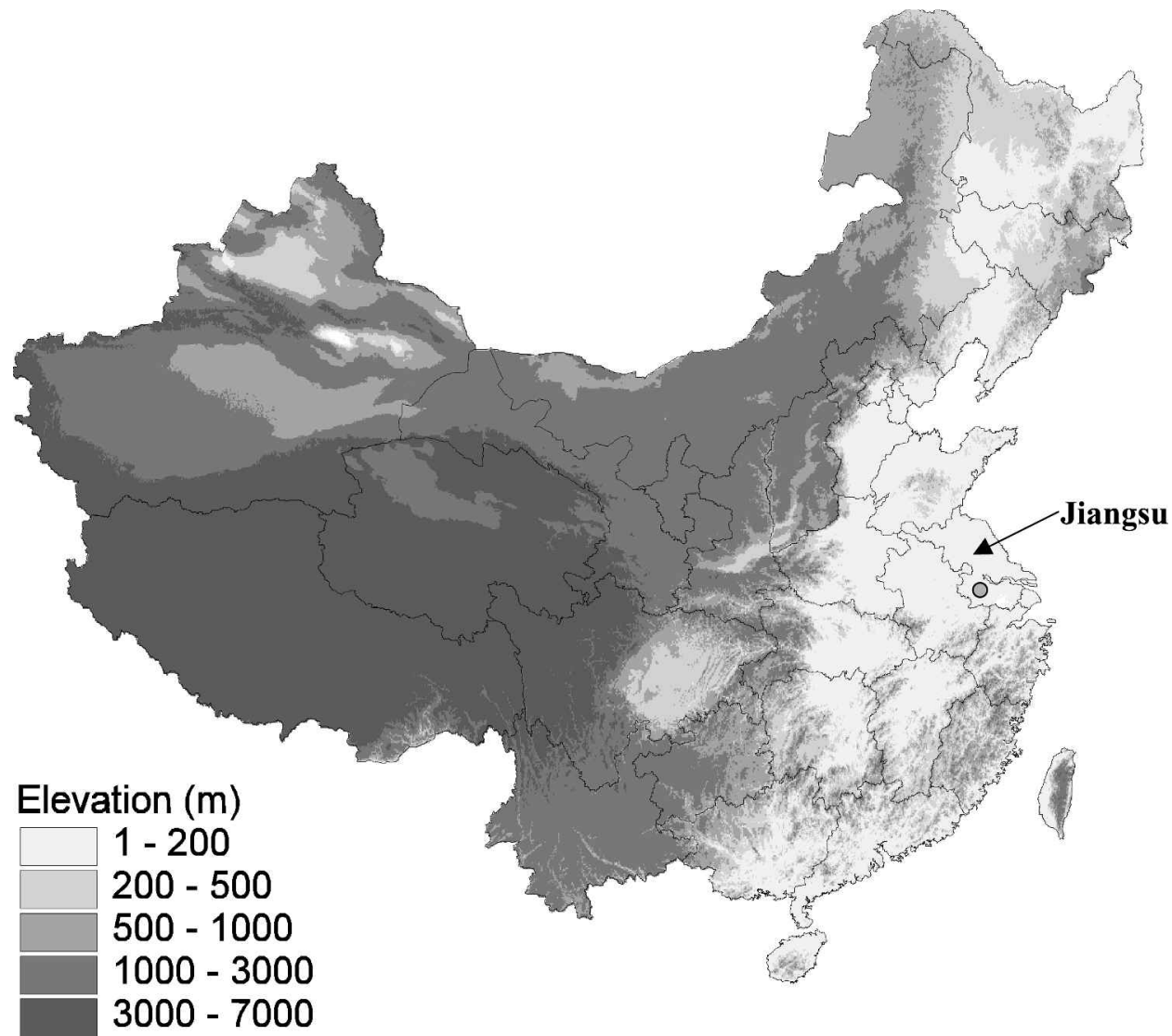

Figure 1. Approximate location of the landscape-scale study area near Nanjing, Jiangsu Province, China (filled black circle). The background of the figure is a digital elevation model at $1 \mathrm{~km}$ resolution, (from the Global Land One Kilometer Base Elevation dataset at the NOAA National Geophysical Data Center (NDGC), see web site http://www.ngdc.noaa.gov/. The polygons in the figure are the provincial boundaries of China.

composite approach that is based on the maximum Normalized Difference Vegetation Index (NDVI) values within a 10-day period for a pixel, which helps minimize the effect of cloud cover and variability in atmospheric optical depth. The four spectral bands (B0, B2, B3, MIR, see table 1) in the VGT-S10 products are the estimates of ground surface reflectance, as atmospheric corrections for ozone, aerosols and water vapour have already been applied to the VGT images using the SMAC algorithm (Rahman and Dedieu, 1994). The ground surface reflectance values of the four spectral bands were used in data analysis. Seven VGT-S10 products from the period 11-20 March up to the end of the period 11-20 May 1999 for the study area were used in this study.

VGT's mid-infrared band (MIR), which is comparable to TM band 5 (table 1), is very sensitive to soil moisture and plant canopy water content. Tucker (1980) suggested that the mid-infrared band (TM5) of TM was best suited for space-borne remote sensing of plant canopy water content. Gao (1996) proposed the Normalized Difference Water Index (NDWI) for remote sensing of vegetation liquid water from 
space, using reflectance values of two near-infrared bands (one band centred approximately at $860 \mathrm{~nm}$, and the other at $1240 \mathrm{~nm}$ ). NDWI was considered to be a complementary vegetation index to the NDVI (Gao 1996, Jürgens 1997). For each of the seven 10-day composites of VGT data, NDWI and NDVI were calculated using the ground surface reflectance values of the spectral bands:

$$
\begin{gathered}
\mathrm{NDWI}_{\mathrm{VGT}}=(\mathrm{B} 3-\mathrm{MIR}) /(\mathrm{B} 3+\mathrm{MIR}) \\
\mathrm{NDVI}_{\mathrm{VGT}}=(\mathrm{B} 3-\mathrm{B} 2) /(\mathrm{B} 3+\mathrm{B} 2)
\end{gathered}
$$

Instead of using the original four spectral bands of the seven VGT-S10 products from 11-20 March to 11-20 May 1999 (a total of 28 bands), the seven 10-day NDVI and NDWI data (a total of 14 bands) were used for image classification. An iterative unsupervised classification approach (ISODATA, ENVI 3.2 version) was applied, with 45 spectral clusters generated. A convergence level of $95 \%$ was assigned, this being the percentage of pixels that do not change clusters between iterations even with a small shift in cluster means. The main advantage of unsupervised classification procedures is that one need not specify a priori the classes and their spectral expression - the aim is to identify all important spectral groupings without initially knowing which are thematically significant (Cihlar et al. 1998). Because the spectral signatures of the same land cover type can differ over large areas (e.g. $175 \times 165 \mathrm{~km}$ ) unsupervised classifications are recommended at this scale (Cihlar et al. 1998).

In this study we used the land cover classification scheme for the International Geosphere and Biosphere Program (IGBP; Loveland et al. 2000, Belward 1996), as it is a well-documented global land cover classification system and our long-term goal is to use VGT data for mapping and monitoring of land cover and vegetation at continental to global scales. The IGBP DIScover Land Cover Classification System (Belward 1996) has 17 land cover classes: evergreen needleleaf forest, evergreen broadleaf forest, deciduous needleleaf forest, deciduous broadleaf forest, mixed forest, closed shrubland, open shrubland, woody savannas, grasslands, persistent wetland, cropland, urban and built-up, cropland/other vegetation mosaic, snow and ice, barren or sparsely vegetated, and water. Various ancillary data were used for interpretation of the 45 spectral clusters in relation to land cover, including the 1:1 000000 Land Use Map of China (Wu 1990), the 1:1 000000 Grassland Resource Map of China (Su 1993), and the Atlas of Forestry in China (Shi 1990). The 45 spectral clusters from the unsupervised classification of multi-temporal VGT data were interpreted, labelled and aggregated into 9 land cover types as defined by the IGBP DIScover Land Cover Classification Scheme.

\section{Landsat TM image and classification method}

One Landsat 5 TM image (Path 120 and Row 38; $30 \mathrm{~m}$ spatial resolution and 7 spectral bands) acquired on 22 April 1996 was used in this study, as it is the only TM image for this region with minimal cloud coverage $(<20 \%$ cloud coverage criterion) during the period of early 1995 to late 1999. The image preprocessing at the ground receiving station includes systematic geometric correction and the image is in the Universal Transverse Mercator (UTM) map coordinates. During field visits to the study area in summer 2000, we collected ground control points (GCPs) for the TM image, which were later used for precision geometric correction of the image. Four TM spectral bands (TM3, 4, 5, 7) were selected for image classification, as the 
three visible bands (TM1, TM2 and TM3) are highly correlated to each other. For visual interpretation of land cover types, NDVI and NDWI of the TM image (see table 1) were calculated using the at-atmosphere reflectance values:

$$
\begin{aligned}
& \mathrm{NDVI}_{\mathrm{TM}}=(\mathrm{TM} 4-\mathrm{TM} 3) /(\mathrm{TM} 4+\mathrm{TM} 3) \\
& \mathrm{NDWI}_{\mathrm{TM}}=(\mathrm{TM} 4-\mathrm{TM} 5) /(\mathrm{TM} 4+\mathrm{TM} 5)
\end{aligned}
$$

The ISODATA unsupervised classification approach was used and 45 spectral clusters were generated. The image was classified with a specified ISODATA convergence threshold of $95 \%$. Two rounds of classification were performed for the image to account for mixed clusters. 'Non-mixed' or 'pure' clusters were assigned a landcover class value and removed from further classification. Land cover classes were assigned based on the analyst's knowledge of the landscape and spectral patterns, and this was aided by ancillary maps and data. 'Mixed' clusters were subject to a second round of clustering. Some clusters remained mixed after two rounds of clustering. Pixels in these clusters were manually assigned to one of the landcover classes.

The 45 spectral clusters from the unsupervised classification of the TM image were interpreted, and labelled and aggregated into 10 land cover types, according to the IGBP DIScover Land Cover Classification Scheme (Loveland et al. 2000, Belward 1996). The resultant TM land cover classification map was re-projected from UTM projection to Lambert Azimuthal Equal Area projection, to be consistent with the VGT data. The TM classification map (30 m spatial resolution) was then co-registered with the VGT classification map ( $1 \mathrm{~km}$ spatial resolution), and aggregated to a $1 \mathrm{~km}$ resolution map using the VGT image as the reference, which facilitates direct comparison with the VGT $1 \mathrm{~km}$ classification map. The aggregated $1 \mathrm{~km}$ TM classification map contains the percentage of each IGBP land cover class within a $1 \mathrm{~km}^{2}$ pixel, and was used to quantify percent fraction of cropland within individual $1 \mathrm{~km} \mathrm{VGT}$ pixels of the VGT classification map.

\section{County-level agricultural census data for cropland area estimates}

County-level agricultural census data for China in 1990 were described in an earlier study (Frolking et al. 1999). The database (hereafter called AC90) contains county statistics on crop areas for twenty major crops, the total area of cropland and the total sown area, which is typically larger than the total cropland area due to double or multiple cropping. Agriculture in the study area is dominated by double cropping systems that consist of either (1) winter wheat and paddy rice or (2) rapeseed and paddy rice. Winter wheat or rapeseed is usually seeded in late October or early November of the previous year, it commences its leaf-on stage in early March, and is harvested in late May to early June. Recently, Chinese researchers (Dr. Liu Chuang, Institute of Geographical Sciences and Natural Resources, Chinese Academy of Sciences, personal communication, 2000) have assembled a digital version of county-level agricultural statistics of China for 1995 (hereafter called AC95). The AC95 database also includes acreage of total cropland for individual counties. Both the AC90 and AC95 databases are consistent with the official cropland statistics reported by the State Statistical Bureau (State Statistical Bureau 1994). Table 2 summarizes the 1990 and 1995 census cropland statistics for the fourteen counties of the study area. In the period 1990 to 1995 , cropland areas were reported to have decreased in all but one county, generally by $1-5 \%$ (table 2 ). The sum of 
$X . X$ iao et al.

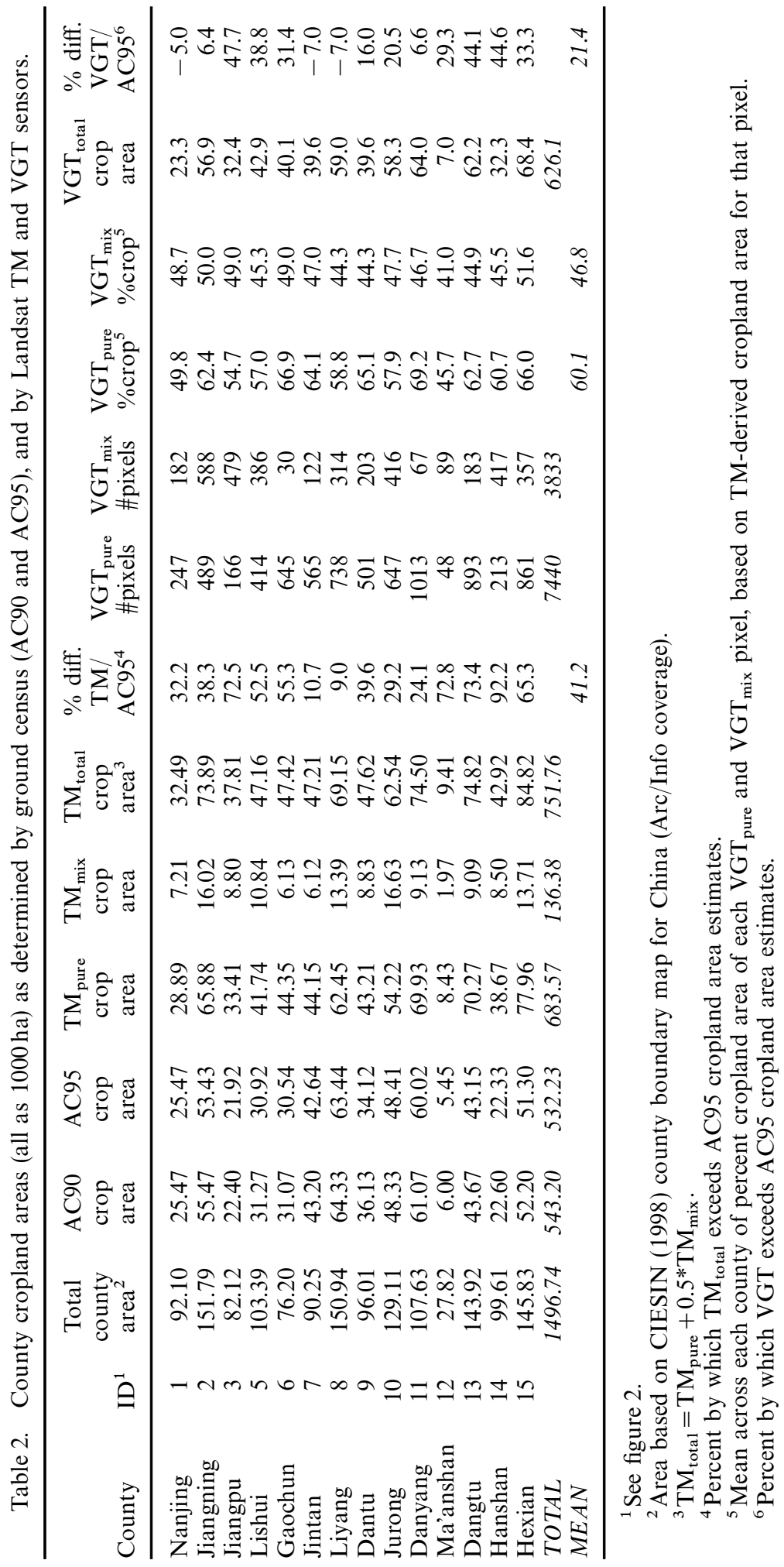


the cropland areas for the fourteen counties in the study area was reported to have decreased by $2 \%$ from 1990 to 1995 .

In this study, a county-level administrative boundary map (1:1000000 scale) representing county borders as of 31 December 1990 (CIESIN 1998) was overlaid on both the VGT-derived and the TM-derived classification maps. Numbers of pixels for individual land cover classes within each county were counted. The derived county-level estimates of cropland area from VGT and TM classification maps were then compared with the AC90/AC95 estimates of total cropland area at county scale.

\section{Results}

\subsection{TM-derived cropland classification}

The false colour composite image (figure 2) clearly shows the spatial patterns of land cover types in the study area. The Yangtze River flows through the study area from southwest to northeast. Other surface water bodies include four large lakes and numerous fish and aquaculture ponds. In late April, winter wheat and rapeseed crops were at the peak of green biomass, and thus had high NDVI and NDWI values (Xiao et al. 2001), resulting in a bluish colour in the false-colour image (figure 2). Cropland was concentrated in the north eastern and south western parts, and accounted for a large portion of the study area. Forests (green colour in figure 2) were mostly distributed in areas of low mountains and hills. According to the global digital elevation model (DEM) data at $1 \mathrm{~km}$ spatial resolution, elevation in the study area varies from $1 \mathrm{~m}$ to $500 \mathrm{~m}$. Of a total area of $28,875 \mathrm{~km}^{2}$, approximately $95.3 \%$ of the land is at an elevation of less than $100 \mathrm{~m}$, and $86.5 \%$ of the land is at an elevation of less than $50 \mathrm{~m}$. Croplands are primarily distributed in low elevation and flat plain areas.

According to the TM classification map (figure 3), cropland accounts for $43 \%$ of the total area of the TM image. Although individual farm families in the study area have 3-5 mu of cropland (Chinese measurement unit of land area, $1 \mathrm{mu}$ equals $1 / 15$ ha or $667 \mathrm{~m}^{2}$ ), dependent upon their family size, the majority of these small holdings lie adjacent to each other in flat areas and thus form large parcels of cropland landscape. However, even using Landsat TM at $30 \mathrm{~m}$ spatial resolution, there was still a significant number of cropland/other natural vegetation mosaic pixels (table 2), mostly attributed to small-scale variations and constraints of topography and soil, resulting in very small parcels of cropland. The cropland/other vegetation mosaic category accounts for $8 \%$ of the total area of the TM image. In the summer of 2000, field surveys were conducted in the study area using a handheld GPS receiver and a GPS camera. Because of budget/time constraints and the agricultural focus of the analysis, the field data collection was biased towards cropland sites (table 3). The field data collected during visits to the study area in the summer of 2000 were used to assess the accuracy of the TM classification for cropland. Of the 44 cropland sites visited during the field surveys, $35(80 \%)$ were classified as 'cropland' or 'cropland/natural vegetation mosaic' in the TM classification (table 3 ).

Agricultural census data and TM-derived cropland area estimates at the county level are compared in table 2. The total TM-derived cropland area in a county was estimated by summing both $\mathrm{TM}_{\text {pure }}$ and $\mathrm{TM}_{\text {mix }}$ areas for that county (table 2):

$$
\text { Total TM-derived cropland area }=\mathrm{b}_{\text {pure }} \times \mathrm{TM}_{\text {pure }}+\mathrm{b}_{\text {mix }} \times \mathrm{TM}_{\text {mix }}
$$

To derive estimates of $b_{\text {pure }}$ and $b_{\text {mix }}$ statistically would require a large sample of aerial photos or space-borne remote sensing data at very fine spatial resolution (e.g. 


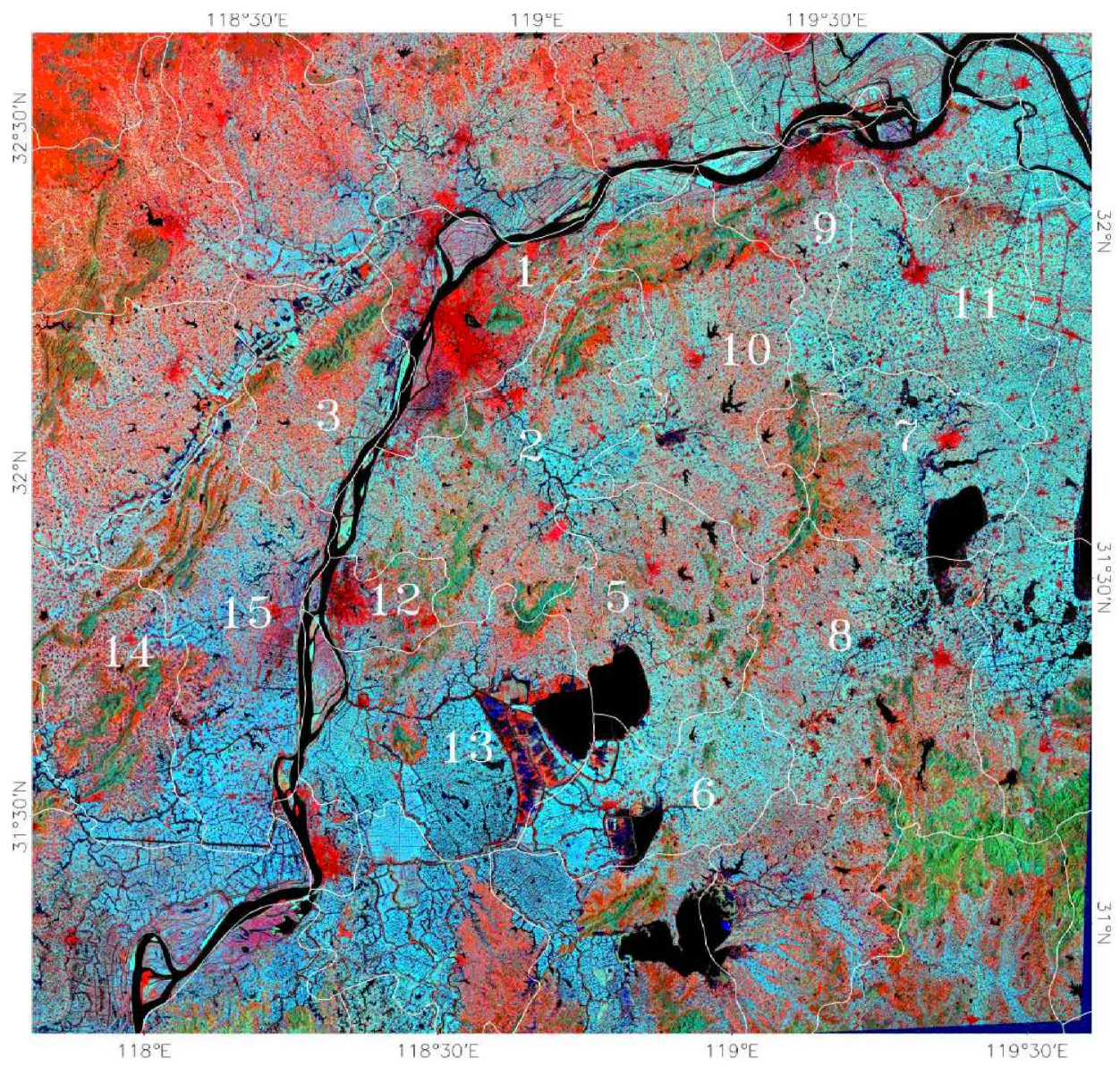

Figure 2. Land cover characteristics in the study area as illustrated by a false colour composite of Landsat TM image acquired on 26 April 1996. The figure was generated using band TM 7 (red), NDVI (green) and NDWI (blue). For TM data, NDVI is calculated using TM4 and TM3, and NDWI is calculated using TM4 and TM5 (see equations (3) and (4), and table 1). In the figure, water bodies are black; forests are green; urban and built-up areas are bright red; croplands are bluish. The borders and numbers identify the counties in the study area (see list in table 2).

$1 \mathrm{~m}$ and $4 \mathrm{~m}$ resolution IKONOS images provided by Space Imaging, Inc.), but these were not available for this study. Therefore, a simple assumption was made for TM data at $30 \mathrm{~m}$ spatial resolution: a $100 \%$ proportion $\left(\mathrm{b}_{\text {pure }}\right)$ of cropland within a cropland pixel $\left(\mathrm{TM}_{\mathrm{pure}}\right)$, and a $50 \%$ proportion $\left(\mathrm{b}_{\text {mix }}\right)$ of cropland within a cropland/other vegetation mosaic pixel $\left(\mathrm{TM}_{\text {mix }}\right)$. The TM-derived estimates of cropland area exceed the 1995 agricultural census data (AC95) for all 14 counties, in a range of $9 \%$ in Liyang County to $92 \%$ in Hanshan County (table 2). The sum of TM-derived cropland area for the 14-county region was 751760 ha, approximately $41 \%$ larger than the AC95 census total.

\subsection{VGT-derived cropland classification}

The false colour composite VGT image on 21-30 April 1999 (figure 4(a)) shows that the spatial pattern of croplands is consistent with the TM false colour image 


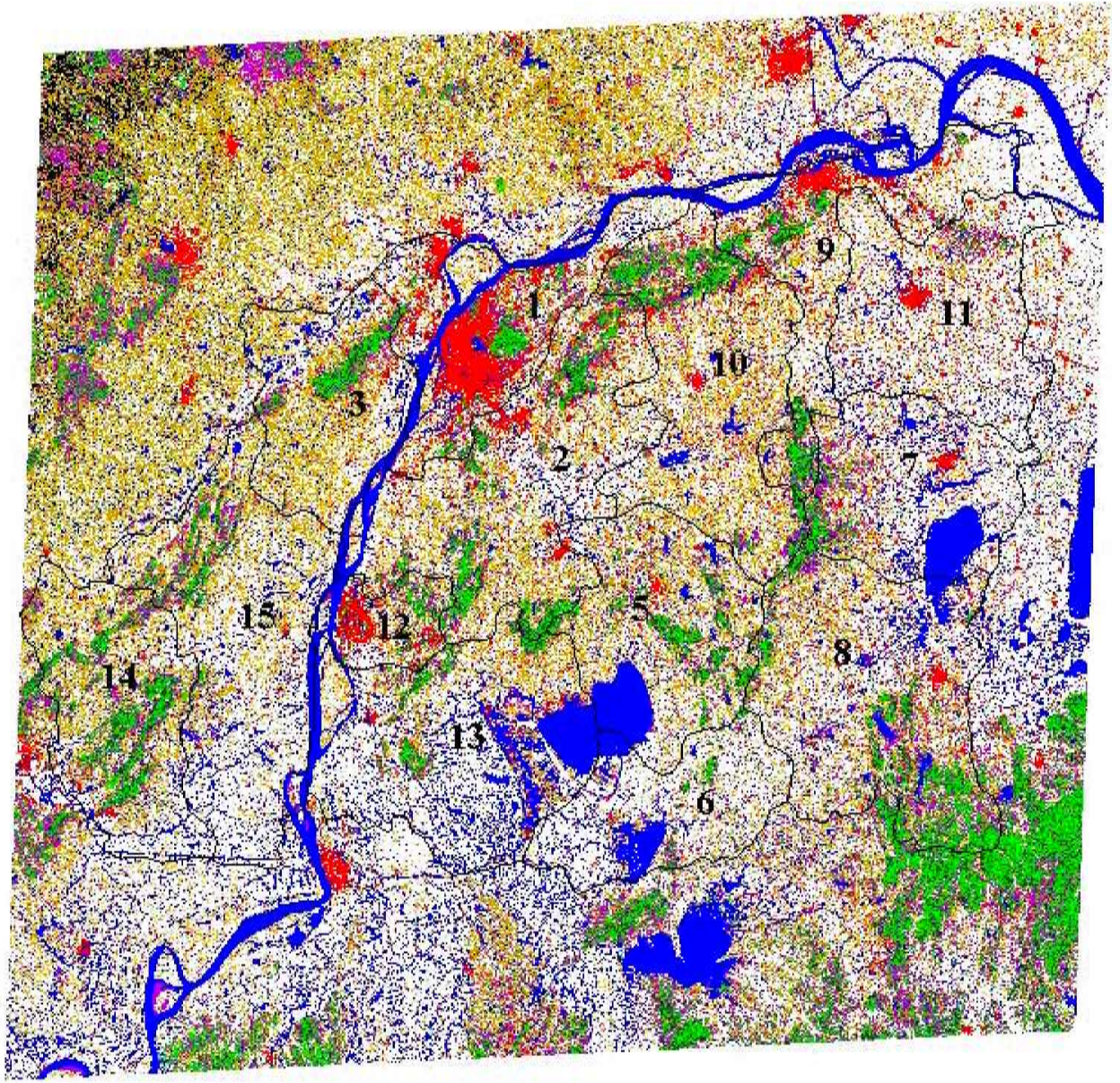

Evergreen Weedleleaf Forest
Mixed Forest
Closed Shrubland
Open Shrubland
Grassland
Cropland
Urban / Built-up
Cropland/Other Natural Veg. Mosaic
Barren / Sparsely Vegetated
Water

Figure 3. Land cover classification map at $30 \mathrm{~m}$ spatial resolution for the study area in Nanjing, Jiangsu Province, China, generated using the TM image acquired on 26 April 1996 (see figure 2). Out of the total area in the TM image, cropland accounts for $43 \%$, cropland/other vegetation mosaic $8 \%$, water $12 \%$, open shrubland $15 \%$, closed shrubland $8 \%$, mixed forest $6 \%$, evergreen forest $2 \%$, grassland $1 \%$, urban/built-up $5 \%$ and bareland $0.006 \%$. 
Table 3. Accuracy assessment of TM classification and VGT classification with a focus on cropland, using the field data collected in the summer of 2000.

\begin{tabular}{|c|c|c|c|c|c|c|c|c|c|c|}
\hline \multirow[b]{2}{*}{ Field data in 2000} & \multicolumn{6}{|c|}{$\begin{array}{l}\text { Classification of TM image } \\
\text { acquired on April 26, } 1996\end{array}$} & \multicolumn{4}{|c|}{$\begin{array}{c}\text { Classification of VGT in } \\
3 / 11-5 / 20,1999\end{array}$} \\
\hline & Cropland & COVM & OS & $\mathrm{CS}$ & Forest & Total & Cropland & COVM & $\mathrm{CS}$ & Total \\
\hline Cropland & 31 & 4 & 4 & 2 & 3 & 44 & 36 & 7 & 1 & 44 \\
\hline Open shrub & 1 & 2 & & & & 3 & 1 & 2 & & 3 \\
\hline Abandoned field ${ }^{1}$ & 1 & & & & & 1 & & 1 & & 1 \\
\hline Total & 33 & 6 & 4 & 2 & 3 & 48 & 37 & 10 & 1 & 48 \\
\hline
\end{tabular}

COVM - cropland/other vegetation mosaic, OS - open shrubland, CS — closed shrubland. ${ }^{1}$ In 2000 , this field had recently been cleared for development, and was likely to have been cropland in 1996 and 1999.

(a)

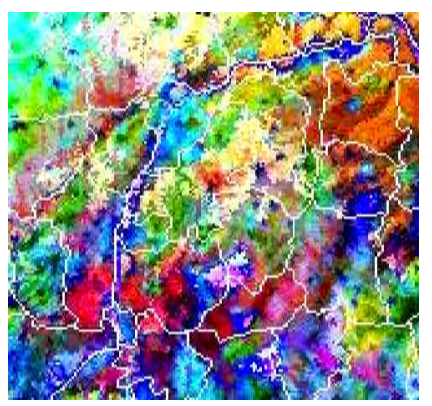

(c)

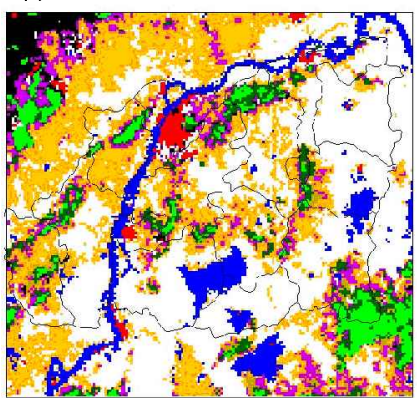

(b)

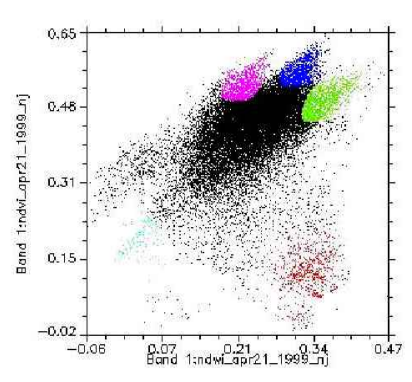

Evergreen Needleleaf Forest

Mixed Forest

Closed Shrubland

Open Shrubland

Grassland

Cropland

Urban / Built-up

Cropland / Other Veg. Mosaic

Water

Figure 4. Land cover characteristics in the study area as illustrated by 10-day synthetic product of VGT images for the study area near Nanjing, Jiangsu Province, China. (a) A false colour composite on 21-30 April 1999, using VGT spectral band B3 (red), MIR (green) and B2 (blue) VGT image in 4/21-30, 1999. (b) A scatter plot of NDVI versus NDWI for VGT pixels on 21-30 April 1999 NDVI vs NDWI in 4/21-30, 1999. (c) VGT-derived land cover classification map at $1 \mathrm{~km}$ spatial resolution VGT classification. (d) Percent cropland within a $1 \mathrm{~km}$ pixel, aggregated from a TM-derived land cover classification map at $30 \mathrm{~m}$ spatial resolution (see figure 3) \% cropland within $1-\mathrm{km}$ pixel. Out of the total area of VGT classification map, cropland accounts for $43 \%$, cropland/other vegetation mosaic $29 \%$, water $8 \%$, open shrubland $2 \%$, closed shrubland $7 \%$, mixed forest $4 \%$, evergreen forest $5 \%$, grassland $3 \%$, and urban/builtup $1 \%$. 
(figure 2) and the TM-derived land cover classification (figure 3). Winter wheat and rapeseed had high biomass and high reflectance values in the near-infrared band. The scatter plot of NDVI and NDWI for all the pixels in the study area shows that croplands have high NDVI and NDWI values (figure 4(b)). NDWI values for croplands in the northeast (blue colour in figure 4(b)) were lower than NDWI values for croplands in the southwest (green colour in figure 4(b)). Forests (red colour in figure 4(b)) had lower NDWI values than croplands, although NDVI values were in a similar range for both forests and croplands.

Using field data collected during visits to the study area in the summer of 2000 (table 3 ), the accuracy of the VGT classification was assessed. Of the 44 cropland sites visited during the field survey, 43 (98\%) were classified as 'cropland' or 'cropland/natural vegetation mosaic' in the VGT classification (table 3). During the field surveys in 2000, relatively homogenous areas of cropland (some several square kilometres in area) were chosen as field points. Because the VGT pixels are $1 \mathrm{~km}^{2}$, these pixels would be classified as 'cropland' even though portions of non-cropland land cover exist in these areas. The spatial patterns of VGT-derived croplands (figure 4(c)) match well with the fractional map of croplands from aggregation of TM-derived land cover types (figure 4(d)). Most VGT-derived cropland pixels (figure 4(c)) are distributed in those areas that have more than $50 \%$ cropland within a $1 \mathrm{~km}$ pixel as illustrated by the TM $1 \mathrm{~km}$ aggregated classification (figure 4(d)). At $1 \mathrm{~km}$ spatial resolution, the number of VGT pixels that were classified as 'cropland' (VGT $_{\text {pure }}$ ) varied from 48 in Ma'anshan City to 1013 in Danyang County (table 2). There were also many pixels classified as 'cropland/other vegetation mosaic' $\left(\mathrm{VGT}_{\text {mix }}\right.$ ) in each county, ranging from 30 in Gaochun County to 588 in Jiangning County (table 2).

Within a $1 \mathrm{~km}$ pixel, the land surface in this part of China is mostly a mix of vegetation (e.g. crops, forests, grass), soil (including bare land, urban and built-up) and water bodies. It is critical to quantify the fraction of cropland within a VGTderived 'cropland' pixel $\left(\mathrm{VGT}_{\text {pure }}\right.$ ) and a VGT-derived 'cropland/other vegetation mosaic' pixel $\left(\mathrm{VGT}_{\text {mix }}\right)$, which may vary significantly over space. For each of the 14 counties, we calculated the fractional cropland area in every $\mathrm{VGT}_{\text {pure }}$ and $\mathrm{VGT}_{\text {mix }}$ pixel, based on $\mathrm{TM}$-derived cropland areas $\left(\mathrm{TM}_{\text {pure }}+\mathrm{TM}_{\mathrm{mix}}\right.$, see equation (5)). For most counties, $\mathrm{VGT}_{\text {pure }}$ pixels had fractional cropland areas ranging from $>40 \%$ to $<80 \%$ (figure 5 ), with mean county values $\left(\mathrm{C}_{\text {pure }}\right)$ ranging from $46 \%$ in Ma'anshan City to $69 \%$ in Danyang County (table 2). TM-derived fractional cropland areas for $\mathrm{VGT}_{\text {mix }}$ pixels were generally less than $60 \%$ (figure 5), with county mean values $\left(\mathrm{C}_{\text {mix }}\right)$ ranging from $41 \%$ in Ma'anshan City to $52 \%$ in Hexian County (table 2$)$. To derive an estimate of total cropland area in a county from the VGT classification data, we multiplied the county mean values $\left(\mathrm{C}_{\text {pure }}\right.$ and $\left.\mathrm{C}_{\text {mix }}\right)$ by the numbers of $\mathrm{VGT}_{\text {pure }}$ and $\mathrm{VGT}_{\text {mix }}$ pixels:

Total VGT-derived cropland area $=\mathrm{C}_{\text {pure }} \times \mathrm{VGT}_{\text {pure }}+\mathrm{C}_{\text {mix }} \times \mathrm{VGT}_{\text {mix }}$

The county-level estimates of total cropland area from the VGT classification (after the sub-pixel correction) range from 7045 ha in Ma'anshan City to 68408 ha in Hexian County (table 2). The differences between the VGT-derived cropland area and the agricultural census data in 1995 at county-level vary from $-7 \%$ in Jintan County to $+45 \%$ in Hanshan County (table 2 ). The VGT-derived cropland area estimate for the 14-county region, using TM-derived sub-pixel cropland fractions of $60 \%$ for pure cropland pixels and $47 \%$ for mixed pixels (table 2), was 626116 ha, 

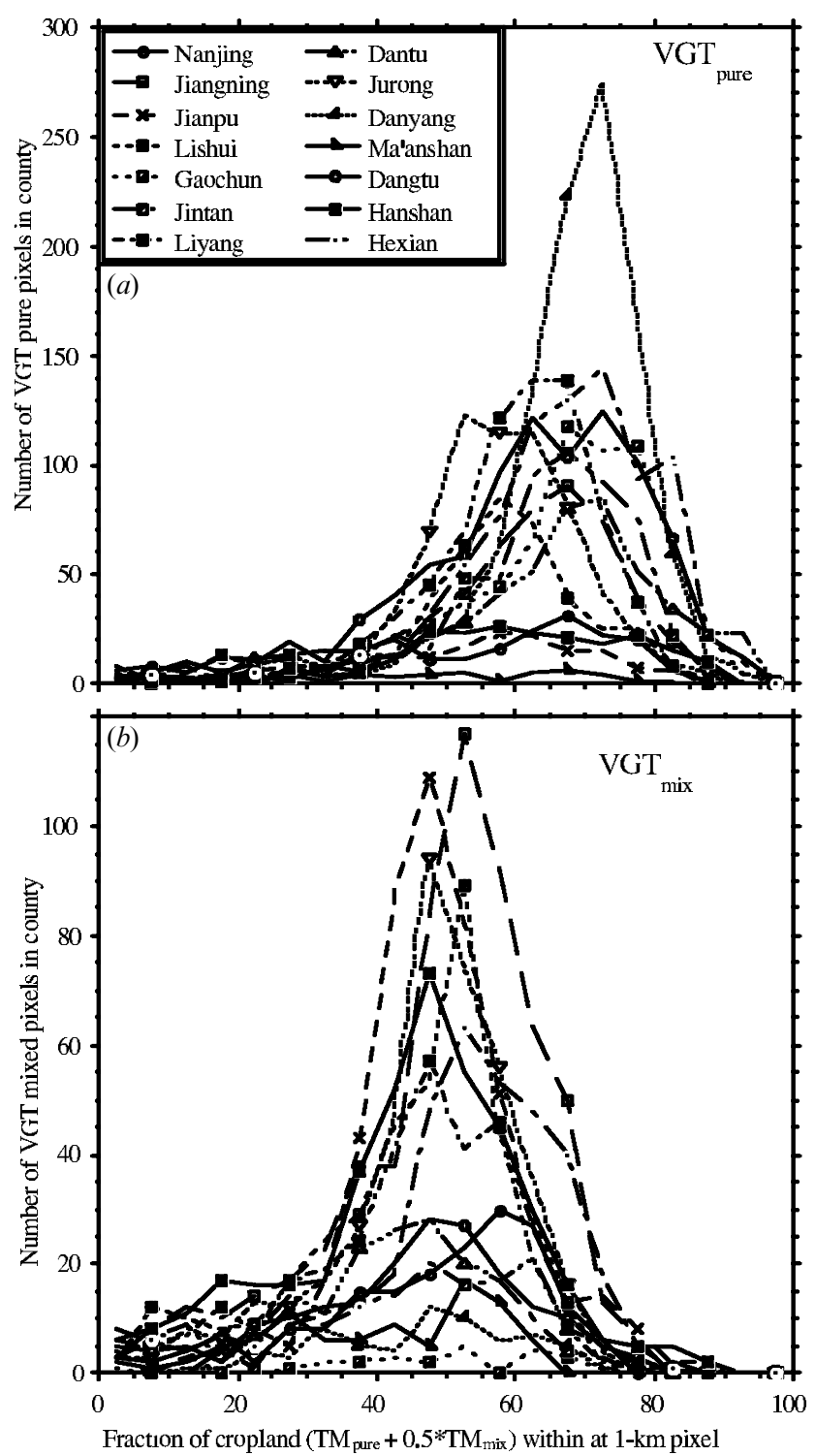

Figure 5. A comparison of VGT-derived cropland estimates $\left(\mathrm{VGT}_{\text {pure }}\right.$ and $\left.\mathrm{VGT}_{\text {mix }}\right)$ and TM-derived cropland estimates $\left(\mathrm{TM}_{\text {pure }}+0.5 \mathrm{TM}_{\text {mix }}\right)$ by county at $1 \mathrm{~km}$ spatial resolution. (a) Histograms for each county of VGT-derived 'Cropland' ( GGT $_{\text {pure }}$ ) pixels with given fractional area of cropland as given by TM classification; (b) Histograms of VGT-derived 'Cropland/other vegetation mosaic' ( $\left.\mathrm{VGT}_{\text {mix }}\right)$.

$21 \%$ greater than the AC95 census total. For all 14 counties, VGT-derived cropland area estimates are smaller than TM-derived cropland area estimates (table 2). This may be attributed mostly to the fact that many crop fields in the study area are small and are distributed in places dominated by other land cover types (e.g. forests; see figures 2, 3, 4(d)), and thus VGT data at $1 \mathrm{~km}$ spatial resolution would not be able to differentiate them. 


\section{Discussion}

In comparison to AVHRR data, the MIR band of the VGT sensor provides additional information on vegetation and land cover. Visual interpretation of VGT images indicates that NDVI and NDWI together provide much better separation of land cover types in the study area of Jiangsu Province, including croplands and forests (figure 4). In an earlier study using Landsat TM data, Jürgens (1997) proposed the term 'modified Normalized Difference Vegetation Index (mNDVI)', which is the same as NDWI, and applied the index to determine frost damage in agriculture, which is not a significant issue in our study area. This landscape-scale study in eastern Jiangsu Province demonstrates the potential of multi-temporal NDVI and NDWI data for image interpretation and characterization of cropland using a perpixel classification approach (e.g. ISODATA unsupervised classifier). Note that multitemporal VGT data were used in this study, but analysis of the bidirectional reflectance distribution function $(\mathrm{BRDF})$ of the land surface was not taken into consideration in preprocessing of VGT-S10 data, which may introduce some uncertainty in land cover classification based on VGT-S10 data. The BRDF can be used to compare observations obtained at different angles or standardize observations to a common geometry ( $\mathrm{Hu}$ et al. 1997). Therefore, further studies are needed to incorporate the BRDF correction into preprocessing of VGT-S10 data and to assess the effect of BRDF in VGT data on land cover characterization at large spatial scales.

During the 1990s, coarse-resolution remote sensing imagery (e.g. AVHRR) was a major data source for large-scale and operational mapping and monitoring of agriculture and land cover change (e.g. Loveland et al. 2000). Several studies have compared cropland estimates derived from AVHRR data with agricultural census data (Ramankutty and Foley 1998, Frolking et al. 1999). Frolking et al. (1999) compared AVHRR-derived estimates of croplands with agricultural census data at the county level (AC90) for more than 2000 counties in China. The AVHRR cropland estimates were extracted from the China Land Cover Characteristics Database which was generated at the US Geological Survey EROS Data Center in cooperation with the Chinese Academy of Surveying and Mapping, using monthly AVHRR-derived NDVI from April 1992 to March 1993 (Z. Zhu, USGS, personal communication, 1997). As the AVHRR-derived land cover database was generated using a per-pixel classification approach (e.g. ISODATA unsupervised classifier), there is no explicit information on sub-pixel heterogeneity or fractional cover of cropland within a $1 \mathrm{~km}$ pixel. A simple assumption was made for cropland fraction within a $1 \mathrm{~km}$ pixel: $100 \%$ cropland for pure cropland pixels and 50\% cropland for mixed cropland/natural vegetation pixels (Frolking et al. 1999); and the resultant estimates of cropland area for the 14 counties in this study area range from 83\% (Danyang County) to 229\% (Ma'anshan City) larger than the AC95 census values, with a mean of $146 \%$. Applying our TM-derived sub-pixel cropland fractions (see table 2) to the above AVHRRbased China Land Cover Characteristics Database, the sum of the AVHRR-derived cropland area estimates for the 14 counties in the study area was 790,449 ha, 53\% higher than the AC95 census total. The official agricultural census datasets for cropland areas are known to underestimate actual cropland area by an estimated 30\% at national scale (Crook 1993, Fischer et al. 1998, Smil 1999). Smil (1999) reported a range of $25-50 \%$ discrepancy between reported cropland area and 'actual' cropland area for Jiangsu Province, with the agricultural census data consistently underestimating the 'actual' cropland area. The TM and VGT analyses in this study also confirm the under-reporting of cropland areas in the AC90 and AC95 census 
datasets. Given the large discrepancies among the agriculture census data, land cover datasets derived from coarse-resolution images (e.g. AVHRR, VGT) and derived from fine-resolution images (e.g. TM) observed at this landscape-scale study and the other study at the national scale (Frolking et al. 1999), caution should be taken in using land cover datasets derived from coarse-resolution image data and per-pixel classification approach. Quantification of sub-pixel heterogeneity would lead to a significant reduction in uncertainty in the coarse-resolution land cover database that might be used for biogeochemical modelling and agricultural production estimation.

For cropland classification using medium to coarse-resolution images and perpixel classification algorithms, classification assessment is critical due to sub-pixel heterogeneity and this could be done at three spatial scales: (1) field-based point survey data (micro-scale); (2) fine-resolution space-borne remote sensing data (e.g. Landsat TM, SPOT) and aerial photo data (medium-scale) and (3) agricultural census data at county level (macro-scale). Field-based surveys require collection of a large sample of field sites, which is usually constrained by limited resources of personnel, time and budget. Over the last two decades, numerous Landsat TM images ( $30 \mathrm{~m}$ spatial resolution) have been used in mapping croplands at many places in the world (e.g. Gonzalez-Alonso et al. 1997, Ortiz et al. 1997), resulting in many fine-resolution maps and databases of cropland and other land cover types. In this landscape-level study we combined fine-resolution TM data, coarse-resolution VGT data, county-level agricultural census data and an administrative county boundary map (GIS). Together with an appropriate statistical sampling design, this would be an efficient and effective approach for obtaining better estimates of cropland areas from county to country scales, using medium-resolution (e.g. MODIS) to coarseresolution (e.g. VGT) sensor data. As an alternative to this approach of per-pixel analysis of coarse-resolution imagery combined with sub-pixel fractions derived from fine-resolution data, we are evaluating the use of spectral mixture analysis of VGT data, and the results will be summarized in another paper. As more cloud-free image data from Landsat 7 ETM +, MODIS and VGT become available over time, which are comparable both temporally and spectrally, efforts to quantify the sub-pixel heterogeneity of land cover types at large spatial scales will be substantially enhanced.

\section{Acknowledgments}

This study was supported by the US multi-agency Terrestrial Ecology and Global Change (TECO) program sponsored by NASA, NSF, DOE, EPA and USDA, and the NASA Earth Observing System (EOS) Interdisciplinary Science (IDS) program. We thank Bo Xu and Rosemarie Rowe for assistance in generating graphs and tables. We thank three anonymous reviewers for their insightful comments and suggestions on the earlier version of the manuscript.

\section{References}

BACHELET, D., 1995, Rice paddy inventory in a few provinces of China using AVHRR data. Geocarto International, 10, 23-38.

Belward, A. S. (ed.), 1996, The IGBP-DIS Global $1 \mathrm{~km}$ Land Cover Data Set "DISCover" Proposal and Implementation Plans, Report of the Land Cover Working Group of IGBP-DIS, IGBP-DIS Working Paper \#13, IGBP Data and Information System Office, Toulouse, France.

CiESiN (Consortium for International Earth Science Information Network), 1998, The China Time Series Administrative Regions GIS Data: 1:1 000000 County Level, prepared by CIESIN, the Chinese Academy of Surveying and Mapping, and China in 
Time and Space (University of Washington), available on the website at http://sedac.ciesin.org/china/admin/bnd90/bnd90.html.

Cihlar, J., Xiao, Q., Chen, J., Beaubiens J., Fung, K., and Latifovic, R., 1998, Classification by progressive generalization: a new automated methodology for remote sensing multichannel data. International Journal of Remote Sensing, 19, 2685-2704.

Crook, F., 1993, Underreporting of China's cultivated land area: Implications for world agricultural trade. China International Agricultural and Trade Report. 1993 Situation and Outlook Series RS-93-4. US Department of Agriculture, Washington, DC, pp. $33-39$.

FANG, H., 1998, Rice crop area estimation of an administrative division in China using remote sensing data. International Journal of Remote Sensing, 19, 3411-3419.

FANG, H., WU, B,. LiU, H., and XuAN, H., 1998, Using NOAA AVHRR and Landsat TM to estimate rice area year-by-year. International Journal of Remote Sensing, 19, 521-525.

Fischer, G., Chen, Y. F., and Sun, L. X., 1998, The balance of cultivated land in China during 1988-1995, Internat. Inst. Appl. Syst. Analysis (IIASA) Interim Report IR-98-047, Laxenburg, Austria.

Frolking, S., XiaO, X., Zhuang, Y., Salas, W., and Li, C., 1999, Agricultural land use in China: A comparison of area estimates from ground-based census and satellite-borne remote sensing, Global Ecology and Biogeography, 8, 407-416.

GAO, B., 1996, NDWI-A normalized difference water index for remote sensing of vegetation liquid water from space. Remote Sensing of Environment, 58, 257-266.

Gonzalez-Alonso, F., Cuevas, J. M., Arbiol, B., and Baulies, X., 1997, Remote sensing and agricultural statistics: crop area estimation in north-eastem Spain through diachronic Landsat TM and ground sample data. International Journal of Remote Sensing, 18, 467-470.

Hu, B., Lucht, W., Li, X., and Strahler, A. H., 1997, Validation of kernel-driven semiempirical models for the surface bidirectional reflectance distribution function of land surface. Remote Sensing of Environment, 62, 201-214.

Jurgens, C., 1997, The modified normalized difference vegetation index (mNDVI)-a new index to determine frost damages in agriculture based on Landsat TM data. International Journal of Remote Sensing, 18, 3583-3594.

Loveland, T. R., Reed, B. C., Brown, J. F., Ohlen, D. O., Zhu, Z., Yang, L., and Merchant, J. W., 2000, Development of a global land cover characteristics database and IGBP DIScover from $1 \mathrm{~km}$ AVHRR data. International Journal of Remote Sensing, 21, 1303-1330.

Lu, D. (ed.), 1997, Applications of Remote Sensing Technology in Agricultural Engineering (Beijing: Qinghua University Press), (in Chinese).

Ortiz, M. J., Formaggio, A. R., and Epiphanio, J. C. N., 1997, Classification of croplands through integration of remote sensing, GIS and historical database. International Journal of Remote Sensing, 18, 95-105.

Quarmby, N. A., Townsend, J. R. G., Settle, J. J., and White, K.H., 1992, Linear mixture modeling applied to AVHRR data for crop area estimation. International Journal of Remote Sensing, 13, 415-425.

Rahman, H., and Dedieu, G., 1994, SMAC: a simplified method for atmospheric correction of satellite measurements in the solar spectrum. International Journal of Remote Sensing, 15, 123-143.

Ramankutty, N., and Foley, J. A., 1998, Characterizing patterns of global land use: an analysis of global croplands data. Global Biogeochemical Cycles, 12, 667-685.

SHI, B. (ed.), 1990, The Atlas of Forestry in China (Beijing: Press of Survey and Mapping), (in Chinese).

Smil, V., 1999, China's agricultural land. China Quarterly, 158, 414-429.

State Statistical Bureau, 1994, Statistical Yearbook of China 1994 (Beijing: China Statistical Publication House), (in Chinese).

Su, D. (ed), 1993, The Atlas of Grassland Resources of China (1:1000 000) (Beijing: Press of Map), (in Chinese).

Tucker, C. J., 1980, Remote sensing of leaf water content in the near-infrared. Remote Sensing of Environment, 10, 23-32.

Wang, J., and XIA, G. (eds), 1996, Remote Sensing of Winter Wheat Using Meteorological Satellites (Beijing: Meteorological Press), (in Chinese). 
Wu, C. (Editor in Chief), 1990, Land-Use Map of China (1:1,000,00 0 scale) (Beijing: Science Press), (in Chinese).

Xiao, X., He. L., Salas, W., Li, C., Moore, B., Zhao, R., Frolking, S., and Boles, S., 2001, Quantitative relationships between field-measured leaf area index and vegetation index derived from VEGETATION images for paddy rice fields. International Journal of Remote Sensing (accepted subjected to revision).

Zhao, R., Wang, Y., and DaI, J. (eds), 1996, Dynamic Monitoring and Production Estimation of Paddy Rice Agriculture in China (Beijing: Press of Science and Technology), (in Chinese). 